\title{
Overweight perception among adolescent girls in relation to appearance of female characteristics
}

\author{
Jolanda S Van Vliet, Leena Rasanen, Per A Gustafsson and Nina Nelson
}

\section{Linköping University Post Print}

\section{Tweet}

N.B.: When citing this work, cite the original article.

Original Publication:

Jolanda S Van Vliet, Leena Rasanen, Per A Gustafsson and Nina Nelson, Overweight perception among adolescent girls in relation to appearance of female characteristics, 2014, Paediatrics and Health, 2(1), 1-7.

http://dx.doi.org/10.7243/2052-935X-2-1

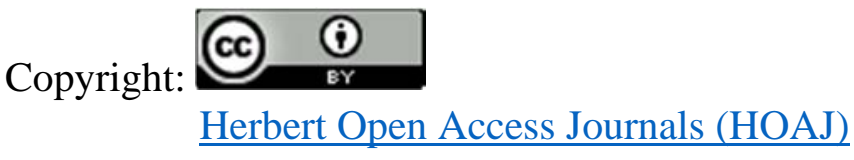

Postprint available at: Linköping University Electronic Press

http://urn.kb.se/resolve?urn=urn:nbn:se:liu:diva-113130 


\title{
Overweight perception among adolescent girls in relation to appearance of female characteristics
}

\author{
Jolanda S. Van Vliet ${ }^{1 *}$, Leena Rasanen ${ }^{2}$, Per A. Gustafsson ${ }^{3}$ and Nina Nelson ${ }^{1}$ \\ *Correspondence: jolanda.van.vliet@lio.se

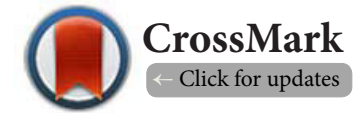 \\ ${ }^{1}$ Faculty of Health Sciences, Department of Clinical and Experimental Medicine, Division of Pediatrics, Linkoping University, Sweden. \\ ${ }^{2}$ Department of Food and Environmental Sciences, Division of Nutrition, University of Helsinki, Finland. \\ ${ }^{3}$ Faculty of Health Sciences, Department of Clinical and Experimental Medicine, Division of Child and Adolescent Psychiatry, \\ Linkoping University, Sweden.
}

\begin{abstract}
Background: Overweight perception has been shown to be important for health related adolescent behavior, particularly in girls. Body perception may be affected by bodily changes, especially changes visible for others. Female pubertal development is characterized by many physical changes, such as accelerated growth and altered body fat distribution. This study examined the role of appearance of female characteristics in the risk for overweight perception among healthy adolescent girls.

Methods: 220 girls, aged 11-16, provided self-reports on body perception and pubertal maturation before anthropometric measurements of height, weight, hip and waist circumference (WC). Logistic regression modeling was used to study the appearance of pubertal characteristics in relation to body perception.

Results: Of the 76 girls (35\%) perceiving themselves as overweight, only 14 and 36 girls were overweight according to body mass index and waist circumference respectively. Girls reporting breast development and acne $(n=144)$ were more likely to perceive themselves as overweight than girls who did not report this appearance $(n=76)$. These findings persist after adjusting for overweight according to WC. Non-overweight $(n=170)$ rather than overweight girls reporting characteristics $(n=50)$ were at risk of perceiving themselves overweight.

Conclusions: Girls may confuse natural changes occurring during adolescent development with being overweight. It is therefore important to improve the understanding about the physical changes that normally occur during puberty along with the girls' own perception of these bodily changes among girls themselves, their parents, at schools, and other healthcare services.
\end{abstract}

Keywords: Adolescent girls, self-reports, body perception, female pubertal development, anthropometric measurements

\section{Introduction}

The concept of body perception or body image is cultural, complex and multidimensional $[1,2]$. Being thin is greatly valued within Western societies and a considerable number of adolescents with normal weight, especially girls, are trying to lose weight to achieve the socially endorsed ideal of a beautiful body $[1,3]$. Both the prevalence and frequency of weight control behavior multiplies as the body mass index increases. At the same time, a high proportion of normal-weight Western girls considering themselves overweight have attempted to lose weight [3]. Self-perception of overweight has in several studies been found to be the most important factor leading to attempts to lose weight $[3,4]$. Health behavior and especially female weight management decision-making is therefore associated more with weight satisfaction than with actual weight, body size or levels of fatness [1,3-5].

Body mass index (BMI) that is used worldwide as a measure of actual body size, correlates poorly with body perception [6]. Waist circumference (WC) has been shown to correlate more closely with body perception than BMI in European adolescent girls [7]. As WC is an important measure of body fat distribution and fat accumulation in the abdominal region [8], this implicates that body perception is related to body fat distribution.

The female pubertal development is characterized by a period of rapid increase in body fat, usually appearing after body hair and breast development have undergone significant changes. An apparent sexual dimorphism in fat patterning is occurring where adolescent girls, compared to prepubertal children and boys, decrease relatively the amount of fat on their waist site and at the same time increase the amount of fat on their hips [9]. This means that girls during their pubertal development get a lower waist hip ratio (WHR) and an apparent "pear" shape compared to prepubertal children and boys, who have, respectively keep, a higher WHR and show a so called "apple"-shape. Menarche typically occurs relatively late in female maturation, after breast growth and fat patterning has started and growth velocity has peaked [10-12].

The relation between total body fat, body fat distribution and 
Van Vliet et al. Paediatrics and Health 2014,

onset of pubertal maturation is controversial [13-17]. A high amount of body fat is believed to promote an earlier maturation $[16,18-20]$. Buyken et al. [21] found that the combination of large WC at the prepubertal stage and early menarche increases the risk of being overweight in late adolescence. However, they conclude that prepubertal body composition may not be critical for initiation of the pubertal growth spurt, but that it affects progression of pubertal development and leads to earlier attainment of later pubertal stages [21]. Several studies show that individuals who mature early or more rapidly tend to have more subcutaneous truncal fat than their peers of the same age $[19,20,22]$.

These naturally occurring physical changes during female pubertal development may contribute to a non-positive body image, since the often rapid increase in body fat in girls is considered to be a negative attribute in Western Europe [23]. The major transition during pubertal development is therefore believed to involve the creation of a "new body image" $[24,25]$. In addition to the influence exerted by fat and weight gain in puberty, breast development itself may drastically alter female self-perception [26]. In general, visible physical changes such as breast development may affect girls more than changes that are less obvious to others $[26,27]$.

Our hypothesis in this study was that overweight perception is influenced by physical changes in adolescence. The purpose of this study was therefore to examine the relationship between perception of overweight and naturally occurring female characteristics during pubertal maturation among healthy Finnish adolescent girls.

\section{Methods}

\section{Participants}

The study population included all girls aged 11-16 years attending school in a small rural town in Finland during 1997-2000 $(\mathrm{N}=348)$. Only data from the 220 girls $(63 \%)$ who participated in both the questionnaire and the anthropometric measurements were analyzed in this study.

Written consent was obtained from both parents and participants before starting any of the measurements. All measurements took place at the school during school hours. All participation was voluntary and the participants were not compensated in any way. The local health centre and the involved schools approved and cooperated with the study.

\section{Instruments}

In order to make future international comparisons possible our questionnaires posed a series of questions from the international WHO survey on Health Behavior in School-aged Children (HBSC) [28].

From the HBSC-questionnaire, we phrased the question "Do you think your body is..." to assess body perception. Response categories were based on the five-point Likert scale and ranged from "far too thin" to "far too fat".

To assess emergence of female characteristics we chose to use self-reported age at menarche and a self-administered rating scale for puberty developed by Carskadon and Acebo [29]. Perception of these characteristics were preferred over the more objective Tanner scale, as perception to a larger extent than actual measures of different body sites and characteristics are believed to affect body perception. A self-rating scale may moreover picture the stage of body consciousness. Items concerning physical development in the scale developed by Carskadon and Acebo included growth spurt, pubic hair growth, skin changes, breast growth, and menstruation. Response options for the first four items were "not yet started," "barely started," "definitely started," "seems complete," and "I don't know" (missing value). Only two answers were possible on the item regarding menstruation: "yes" or "no" and if "yes," the follow-up question was "age at menarche".

In addition to the qualitative self-reported data by questionnaires, physical measurements of height, weight, waist and hip circumference were obtained. Height was measured to the nearest $0.1 \mathrm{~cm}$ and weight to the nearest $0.1 \mathrm{~kg}$. Hip circumference $(\mathrm{cm})$ was measured at the widest point to the nearest $0.1 \mathrm{~cm}$. Waist circumference $(\mathrm{cm})$ was measured to the nearest $0.1 \mathrm{~cm}$ midway between the tenth rib and the iliac crest.

\section{Procedure}

Oral and written presentations of the study were given to both the girls, in their class room during school hours, and to their parents, who were invited to a special parental evening at school. Information was included on how the girls' integrity was ensured by taking the measurements individually in privacy and by encoding every participant immediately after consent. The girls completed the questionnaire in the classroom where the researchers were present to ensure privacy and individually completion of the questionnaire. After that, the anthropometric measures were obtained individually in privacy by the researchers using calibrated school equipment. All measurements were made at school during school hours.

In addition to the directly obtained physical measurements, we calculated body mass index (BMl=weight/height $\left.{ }^{2}\right)$ and waist-hip ratio (WHR) for each respondent. The adolescents' weight statuses were categorized by means of the age- and gender-specific BMI cut-off points for overweight and obesity presented by Cole et al. [30]. Cole and coworkers did not present any cut-off points for underweight and severe underweight in their study [30] and as in this study the focus is on overweight and overweight perception, only three categories obese, overweight and non-overweight were used. For the age- and gender specific cut-off points for overweight according WC, we used the percentiles developed by McCarthy et al. [31].

From the answer on the question on body weight perception, overweight perception was defined by a score of four or higher on the Likert scale. Body perception was dichotomized in non-overweight and overweight perception as the focus in this study was on overweight perception. Of the 144 girls 
perceiving themselves non-overweight, only 16 girls reported themselves being too thin. None of the 16 girls perceiving themselves too thin were measured overweight according to $\mathrm{BMI}$ or according to WC.

In the analyses of the self-administered rating scale for puberty we chose to treat the items on pubertal maturation separately, rather than calculating a total score as proposed by Carskadon and Acebo, since responses to the different items varied for each individual. The responses "not yet started" and "barely started" were categorized into "not started," while "definitely started" and "seems complete" were categorized into "started". The reason for including "barely started" in "not started" was the small group of individuals in the category "not started", probably due to the fact that the age of the girls in this study started at 11 years when most girls start to show some signs of development. The pubertal maturation scale was dichotomized to diminish the individual variation due to the girls' uncertainty on the exact place on the response scale and to be able to calculate the odds ratios of the different pubertal characteristics for overweight perception.

\section{Data analysis}

The information collected was coded and entered into the statistics program SPSS 19.0. To compare girls perceiving themselves as overweight with those not perceiving themselves as overweight, the t-test was used for continuous variables and the chi-square test for non-parametric variables.

We used univariate logistic regression modeling to study the appearance of pubertal characteristics in relation to body perception and logistic regression to assess odds ratios of overweight perception. Logistic regression answered the question whether likelihood for overweight perception varies with independent variables such as secondary pubertal characteristics. We also calculated crude odds ratios from cross-tabulations. The crude odds ratio (OR) for overweight perception for girls classified as overweight based on BMI was 41.63 with a confidence interval $(\mathrm{Cl})$ of 5.46-317.15. The high $\mathrm{OR}$ and wide $\mathrm{Cl}$ were due to having just a single person in the cross-tabulation cell for non-overweight perception and overweight according BMI which reflects instability in the results. Another effect of having a single person in one of the cells in the cross-tabulation was that classification of overweight according to BMI cannot be used in multiple regression modeling since zero will occur in at least one of the cells. Multiple regression modeling was therefore used to adjust for measured overweight according to WC only. Due to attrition, the number of subjects in separate analyses varied depending on what variables were included. The level of significance for all analyses was set at $\mathrm{p}<0.05$.

\section{Results}

Of all girls participating ( $n=220), 15$ girls $(7 \%)$ were measured overweight or obese while 76 girls (35\%) perceived themselves as overweight. Table 1 shows a comparison of the prevalence
Table 1. Prevalence (\%) of overweight and Prevalence (\%) of overweight perception among 11-, 13- and 15-year old Finnish girls in the current study compared to the Finnish results of the HBSC-study by survey year [43].

\begin{tabular}{lllllll}
\hline & \multicolumn{3}{c}{$\begin{array}{c}\text { Prevalence (\%) of } \\
\text { Overweight }\end{array}$} & \multicolumn{3}{c}{$\begin{array}{c}\text { Prevalence (\%) of } \\
\text { Overweight Perception }\end{array}$} \\
\hline & 11-year & 13-year & 15-year & 11-year & 13-year & 15-year \\
\hline $\begin{array}{l}\text { Current study } \\
\text { 97-00 }\end{array}$ & 8 & 13 & 6 & 40 & 38 & 40 \\
$\begin{array}{l}\text { HBSC Finland } \\
\text { 01/02 }\end{array}$ & missing & 11 & 9 & 31 & 42 & 43 \\
$\begin{array}{l}\text { HBSC Finland } \\
\text { 05/06 }\end{array}$ & 16 & 11 & 12 & 35 & 44 & 45 \\
$\begin{array}{l}\text { HBSC Finland } \\
\text { 09/10 }\end{array}$ & 13 & 14 & 11 & 35 & 47 & 49 \\
\hline
\end{tabular}

${ }^{1}$ Criteria for overweight, including obesity, according BMI: IOTF [30].

${ }^{2}$ Prevalence of overweight in the current study is based on measured data of height and weight, while the prevalence of overweight in the HBSC-surveys in Finland are based on selfreported data of height and weight. In the current study the correlation coefficient between measured and self-reported BMI was $0.94(\mathrm{P}<0.01)$.

of overweight, including obesity, and the prevalence of overweight perception among girls in the present study and girls participating in the HBSC-surveys in Finland in 1997/1998, 2001/2002, 2005/2006 and 2009/2010. Girls in the present study had a comparable low prevalence for overweight as well as for overweight perception. Of all girls perceiving themselves as overweight in the present study $(n=76)$, only 14 $(18 \%)$ and 36 girls (47\%) were actually measured and classified as overweight according to their BMI and WC respectively.

Table 2 describes the physical characteristics of the group of girls who perceived themselves as overweight compared with the group of girls who did not. Girls with overweight perception ( $n=76)$ had significantly higher weight, BMI, WC, hip circumference and WHR than girls without over-

Table 2. Mean and standard deviations (SD) for height, weight, body mass index (BMI), waist circumference (WC), hip circumference, waist-hip ratio (WHR), age, and age at menarche in girls perceiving themselves as overweight compared with girls not perceiving themselves as overweight.

\begin{tabular}{llllll}
\hline & $\begin{array}{c}\text { Girls perceiving } \\
\text { themselves as } \\
\text { overweight }\end{array}$ & $\begin{array}{c}\text { Girls not perceiving } \\
\text { themselves as } \\
\text { overweight }\end{array}$ & \\
\hline Variable & Mean (SD) & N & Mean (SD) & N & P \\
\hline Height & $159.5(7.2)$ & 76 & $157.0(8.0)$ & 144 & $<0.05$ \\
Weight & $54.1(9.6)$ & 76 & $45.1(7.8)$ & 144 & $<0.01$ \\
BMI & $21.2(2.8)$ & 76 & $18.2(1.8)$ & 144 & $<0.01$ \\
WC & $70.3(8.1)$ & 76 & $63.6(4.4)$ & 144 & $<0.01$ \\
Hip Circumference & $91.4(7.8)$ & 76 & $84.6(6.5)$ & 144 & $<0.01$ \\
WHR & $0.77(0.00)$ & 76 & $0.75(0.01)$ & 144 & $<0.05$ \\
Age & $13.7(1.5)$ & 76 & $13.5(1.4)$ & 144 & $\mathrm{~ns}$ \\
Age at menarche & $12.4(1.0)$ & 50 & $12.7(1.0)$ & 81 & $\mathrm{~ns}$ \\
\hline
\end{tabular}


Van Vliet et al. Paediatrics and Health 2014,

weight perception ( $n=144)$. No significant differences were found between the groups in chronological age or in age at menarche.

Table 3 shows how the girls reported their perception of the stage of each of the female characteristics. Most missing values ("I don't know) were found for self-report on the stage for growth spurt and acne. How the girls' perceived stage of each of the female pubertal characteristics affected overweight perception is presented as results of the univariate logistic regression modeling in Table 4. The results show that the likelihood of overweight perception increased significantly among girls reporting apparent breast growth and girls reporting apparent acne $(p<0.05)$. After adjusting for overweight classification according to WC, the increased likelihood of overweight perception persisted both among girls reporting breast growth and girls reporting acne $(p<0.05)$. No significant interaction factor was found for breast growth

Table 3. Number of girls (\% of all girls) reporting perceived stage for each of the pubertal characteristics $(n=220)$.

\begin{tabular}{llll}
\hline & Not started & Started & I don't know \\
\hline Growth spurt & $86(39 \%)$ & $87(40 \%)$ & $47(21 \%)$ \\
Pubic hair & $68(31 \%)$ & $146(66 \%)$ & $6(3 \%)$ \\
Acne & $86(39 \%)$ & $118(54 \%)$ & $16(7 \%)$ \\
Breast growth & $76(35 \%)$ & $144(65 \%)$ & $0(0 \%)$ \\
Menarche & $82(37 \%)$ & $138(63 \%)$ & $0(0 \%)$ \\
\hline
\end{tabular}

and WC or for acne and WC. The interaction factor is therefore omitted from further analysis.

For comparison of the impact of emergence of breast growth or acne among non-overweight and overweight girls, odds ratios were calculated separately for these groups and presented in Table 5. Table 5 shows that the likelihood of overweight perception was significantly increased among non-overweight girls when reporting apparent breast growth $(p<0.01)$.

\section{Discussion}

This study illustrates how appearance of female pubertal characteristics affects body perception among adolescent girls. In particular we found that characteristics visible to others, such as breast growth and acne, increased the likelihood of overweight perception, especially in non-overweight girls.

Perception of the body and its development has an important role in self-evaluation, mental health and psychological well-being [32]. It is therefore not surprising that the majority of disturbances in body perception start during adolescence, a period of rapid physiological changes [33]. In our previous work, waist circumference (WC) was found to correlate more closely with body perception than BMI in adolescent girls [7], implicating that body fat distribution mediates body size estimation. Rhodes et al. [34] showed that obese women with prominent body fat distribution concentrated in visible areas such as the face, chest, and waist, overestimate their

Table 4. Logistic univariate regression model predicting odds ratios (OR), 95\% confidence intervals (CI), and significance of perceived emergence of each of the secondary pubertal characteristics, for overweight perception. Overweight perception adjusted for overweight based on WC in a multiple regression model predicting OR, 95\% CI, and significance for each pubertal characteristic.

\begin{tabular}{|c|c|c|c|c|c|}
\hline \multirow[t]{2}{*}{ Female characteristics } & & & \multicolumn{3}{|c|}{ adjusted for overweight based on WC } \\
\hline & $\begin{array}{l}\text { OR when perceived } \\
\text { "not started" }\end{array}$ & $\begin{array}{l}\text { OR when perceived } \\
\text { "started" }\end{array}$ & $\begin{array}{l}\text { CI perceived } \\
\text { "started" }\end{array}$ & $\begin{array}{l}\text { OR when perceived } \\
\text { "started" }\end{array}$ & CI perceived "started" \\
\hline Breast growth $(n=220)$ & 1.00 & $2.83^{*}$ & $1.51-5.31$ & $2,73^{*}$ & $1.36-5.47$ \\
\hline Acne $(n=203)$ & 1.00 & $2.56^{*}$ & $1.42-4.60$ & $2.02^{*}$ & $1.07-3.82$ \\
\hline Pubic hair growth $(n=214)$ & 1.00 & 1.33 & $0.73-2.42$ & 1.37 & $0.70-2.66$ \\
\hline Growth spurt $(\mathrm{n}=173)$ & 1.00 & 1.30 & $0.72-2.35$ & 1.04 & $0.55-1.99$ \\
\hline Menstruation $(n=220)$ & 1.00 & 1.55 & $0.88-2.74$ & 1.45 & $0.77-2.73$ \\
\hline
\end{tabular}

${ }^{*} \mathrm{p}<0.05$

Table 5. Logistic univariate regression model predicting odds ratios (OR), 95\% confidence intervals (CI), for overweight perception among non-overweight and overweight girls respectively that report the apparent physical characteristics breast growth and acne. Overweight classification is based on WC.

\begin{tabular}{lcccc}
\hline Perceived appearance of: & $\begin{array}{c}\text { OR (95\% CI) for overweight perception } \\
\text { among Non-Overweight girls }\end{array}$ & $\begin{array}{c}\text { OR (95\% CI) for overweight perception } \\
\text { among Overweight girls }\end{array}$ \\
\hline Breast growth & $\mathrm{n}=170$ & $3.57(1.47-8.66)^{* *}$ & $\mathrm{n}=50$ & $1.94(0.51-7.47)$ \\
Acne & $\mathrm{n}=155$ & $2.02(0.95-4.33)$ & $\mathrm{n}=48$ & $1.81(0.47-6.97)$ \\
\hline
\end{tabular}

${ }^{* *} \mathrm{p}<0.01$ 
Van Vliet et al. Paediatrics and Health 2014,

body size and feel heavier than they actual are. Moreover, Bergström and coworkers [35] showed that Swedish female adolescents and young adults overestimate different body sites, especially waist, buttocks, thighs, and chest. These results are confirmed by our study, where girls who perceived themselves as overweight had in fact a larger WC and hip circumference (Table 2), which are both important measures of visible female body fat distribution [9]. Furthermore, we found a significant higher WHR among girls perceiving themselves as overweight (Table 2), indicating that the relative higher fat deposition in the abdominal region and a lesser "pear"-shaped body plays an important role in girls' overweight perception. With regard to this risk for overweight perception, an important question remains whether the higher amount of body fat in the abdominal region is the cause or an effect of the stage of female pubertal development.

Of the characteristics appearing during pubertal development, especially physical changes observable by others, such as breast development and skin changes like acne, affected body perception more than changes and characteristics less obvious to others, such as menarche. Brooks-Gunn and coworkers noted long ago that perceived breast growth may, at least at the very start, be associated with a more positive body image in contrast to fat increase at other sites of the body [27], but this is left without further attention in recent research. Our results could also confirm the findings of Rhodes et al. [34] mentioned above that body fat in visible areas such as the face, chest and waist leads to an overestimation of body size.

Our finding that the likelihood of overweight perception was even more increased in non-overweight girls strengthens the fact that visible physiological changes affect the girls' body perception. For non-overweight girls, physical changes in body fat distribution and breast growth are more obvious, both to themselves and to others. Especially breast growth that initially can be experienced as positive by the girls can become distressing later in the developmental process, since it reflects the characteristically female accumulation of body fat, not just around the breasts, but also as a general increase in body fat [11]. The fact that self-reports on the stage of breast development did not have any missing values ("I don't know) in contrast to the number of missing values on the stage for growth spurt, implicate that school-aged girls themselves are aware of the process of breast development and can therefore easily respond to this item [36]. Self-reported breast growth could therefore be used as an indicator of the female accumulation of body fat, in addition to WC as a measure for abdominal fat, to assess body perception and the risk for overweight perception in girls during their pubertal development.

When discussing pubertal development it is important to note the secular trend in pubertal timing over the past century. Age at menarche decreased dramatically during the first half of the twentieth century in Western nations. From 1960 onwards, the trend towards earlier onset of menarche has slowed and actually reversed in some societies [14,37-38]. However, modern studies found significantly earlier breast development among girls who were born more recently [38-41]. Thus, a secular trend toward earlier breast development may raise some alarm, considering the association between breast development and overweight perception shown in this study.

One limitation of the present study is the lack of longitudinal data on girls before they enter puberty and throughout the maturation process to study cause and effects of body fat distribution at different pubertal stages. Buyken et al. noted that prepubertal body composition affects progression of pubertal development, leading to earlier attainment of later pubertal stages [21]. American girls with breast development as the initial manifestation of puberty had more body fat not only at onset of puberty, but also one year prior to pubertal maturation. These girls also experienced earlier onset of menarche, and had a larger WC [14]. None of these theories can be studied here.

In this study, a rather homogeneous population was taken from a small rural town in Finland and the period of data collection was some years ago, both potential limitations on the implications of the results. However, in the comparison of prevalence of overweight and overweight perception with the results of the HBSC-surveys in Finland (Table 1), there were no indications that overweight and overweight perception would not to be a problem today. Also Ojala et al. concluded that there was no significant difference in self-perceived weight or body satisfaction between the HBSC-survey years in Finland [42]. On the contrary, the proportion of overweight and obese adolescents has increased in the Western world, there is still a great value placed on a thin appearance and, at the same time, secular trend in pubertal timing especially with respect to an earlier breast development is ongoing. Further research concerning body perception during female pubertal development in various populations is valuable for creating knowledge based strategies in future school health.

\section{Conclusions}

We conclude that girls, especially non-overweight girls, may confuse the natural physical changes occurring during female pubertal development with being overweight. It is therefore important to regard the own perception of the whole body along with objective assessment of the body. The understanding about the physical changes that normally occur during puberty along with the girls' own perception of these bodily changes needs to be improved among girls themselves, their parents, at schools, and other healthcare services. We wish to emphasize the importance of raising the issue of the girls' own body perception with adolescent girls to facilitate health awareness for their future health and health behaviors.

\section{Competing interest}

The authors declare that they have no competing interests. 
Van Vliet et al. Paediatrics and Health 2014,

http://www.hoajonline.com/journals/pdf/2052-935X-2-1.pdf

doi: $10.7243 / 2052-935 X-2-1$

\section{Authors' contributions}

\begin{tabular}{|l|c|c|c|c|}
\hline Authors' contributions & JSV & LR & PAG & NN \\
\hline Research concept and design & $\checkmark$ & $\checkmark$ & -- & -- \\
\hline Collection and/or assembly of data & $\checkmark$ & $\checkmark$ & -- & -- \\
\hline Data analysis and interpretation & $\checkmark$ & $\checkmark$ & $\checkmark$ & $\checkmark$ \\
\hline Writing the article & $\checkmark$ & $\checkmark$ & $\checkmark$ & $\checkmark$ \\
\hline Critical revision of the article & $\checkmark$ & $\checkmark$ & $\checkmark$ & $\checkmark$ \\
\hline Final approval of article & $\checkmark$ & $\checkmark$ & $\checkmark$ & $\checkmark$ \\
\hline Statistical analysis & $\checkmark$ & $\checkmark$ & $\checkmark$ & $\checkmark$ \\
\hline
\end{tabular}

\section{Acknowledgement}

The authors would like to thank the students at Helsinki University who assisted in data collection. We would also like to thank the entire staffs of the enrolled schools for their time and support during the data collection periods. We wish to express our gratitude to the Juho Vainio Foundation, the Finnish Cultural Foundation, and the Erik Johan Ljungberg Educational Fund for financial support.

Publication history

Senior Editor: Victor C. Strasburger, UNM School of Medicine, USA. Received: 26-Nov-2013 Revised: 23-Dec-2013

Re-Revised: 24-Dec-2013 Accepted: 08-Jan-2014

Published: 27-Jan-2014

\section{References}

1. Page A and Fox KR. Is body composition important in young people's weight management decision-making? Int J Obes Relat Metab Disord. 1998; 22:786-92. | Article | PubMed

2. Bergstrom $E$, Stenlund $H$ and Svedjehall B. Assessment of body perception among Swedish adolescents and young adults. J Adolesc Health. 2000; 26:70-5. | Article | PubMed

3. Strauss RS. Self-reported weight status and dieting in a crosssectional sample of young adolescents: National Health and Nutrition Examination Survey III. Arch Pediatr Adolesc Med. 1999; 153:741-7. I Article | PubMed

4. Ojala K, Vereecken C, Valimaa R, Currie C, Villberg J, Tynjala J and Kannas L. Attempts to lose weight among overweight and non-overweight adolescents: a cross-national survey. Int I Behav Nutr Phys Act. 2007; 4:50. | Article | PubMed Abstract | PubMed Full Text

5. Mikkila V, Lahti-Koski M, Pietinen P, Virtanen SM and Rimpela M. Associates of obesity and weight dissatisfaction among Finnish adolescents. Public Health Nutr. 2003; 6:49-56. | Article | PubMed

6. Goodman E, Hinden BR and Khandelwal S. Accuracy of teen and parental reports of obesity and body mass index. Pediatrics. 2000; 106:52-8. | Article | PubMed

7. Van Vliet JS, Kjolhede EA, Duchen K, Rasanen L and Nelson N. Waist circumference in relation to body perception reported by Finnish adolescent girls and their mothers. Acta Paediatr. 2009; 98:501-6. | Article | PubMed

8. McCarthy HD. Body fat measurements in children as predictors for the metabolic syndrome: focus on waist circumference. Proc Nutr Soc. 2006; 65:385-92. | Article | PubMed

9. Taylor RW, Grant AM, Williams SM and Goulding A. Sex differences in regional body fat distribution from pre- to postpuberty. Obesity (Silver Spring). 2010; 18:1410-6. | Article | PubMed

10. Bourguignon JP and Juul A. Normal female puberty in a developmental perspective. Endocr Dev. 2012; 22:11-23. | Article | PubMed

11. Rodriguez-Tome H, Bariaud F, Zardi MF, Delmas C, Jeanvoine B and Szylagyi $P$. The effects of pubertal changes on body image and relations with peers of the opposite sex in adolescence. J Adolesc. 1993; 16:421-

\section{8. | Article | PubMed}

12. Apter $D$ and Hermanson E. Update on female pubertal development. Curr Opin Obstet Gynecol. 2002; 14:475-81. | Article | PubMed

13. Aksglaede L, Juul A, Olsen LW and Sorensen TI. Age at puberty and the emerging obesity epidemic. PLoS One. 2009; 4:e8450. | Article | PubMed Abstract | PubMed Full Text

14. Biro FM, Lucky AW, Simbartl LA, Barton BA, Daniels SR, Striegel-Moore $R$, Kronsberg SS and Morrison JA. Pubertal maturation in girls and the relationship to anthropometric changes: pathways through puberty. $J$ Pediatr. 2003; 142:643-6. | Article | PubMed

15. Bratberg GH, Nilsen TI, Holmen TL and Vatten LJ. Combined influence of early sexual maturation and central adiposity on subsequent stature. A four-year follow-up of 1,605 Norwegian boys and girls: the Young-HUNT study. Eur J Pediatr. 2006; 165:787-93. | Article | PubMed

16. Davison KK, Susman EJ and Birch LL. Percent body fat at age 5 predicts earlier pubertal development among girls at age 9. Pediatrics. 2003; 111:815-21. | Article | PubMed Abstract | PubMed Full Text

17. Hillman JB and Biro FM. Dynamic changes of adiposity during puberty: life may not be linear. J Adolesc Health. 2010; 47:322-3. | Article | PubMed

18. Biro FM, Khoury $P$ and Morrison JA. Influence of obesity on timing of puberty. Int J Androl. 2006; 29:272-7. | Article | PubMed

19. Bratberg GH, Nilsen TI, Holmen TL and Vatten LJ. Early sexual maturation, central adiposity and subsequent overweight in late adolescence. a four-year follow-up of 1605 adolescent Norwegian boys and girls: the Young HUNT study. BMC Public Health. 2007; 7:54. | Article | PubMed Abstract | PubMed Full Text

20. Kaplowitz PB, Slora EJ, Wasserman RC, Pedlow SE and Herman-Giddens ME. Earlier onset of puberty in girls: relation to increased body mass index and race. Pediatrics. 2001; 108:347-53. | Article | PubMed

21. Buyken AE, Karaolis-Danckert $\mathrm{N}$ and Remer T. Association of prepubertal body composition in healthy girls and boys with the timing of early and late pubertal markers. Am J Clin Nutr. 2009; 89:221-30. | Article | PubMed

22. Kindblom JM, Lorentzon M, Norjavaara E, Lonn L, Brandberg J, Angelhed JE, Hellqvist A, Nilsson S and Ohlsson C. Pubertal timing is an independent predictor of central adiposity in young adult males: the Gothenburg osteoporosis and obesity determinants study. Diabetes. 2006; 55:3047-52. | Article | PubMed

23. Latner JD and Stunkard AJ. Getting worse: the stigmatization of obese children. Obes Res. 2003; 11:452-6. | Article | PubMed

24. Eisenberg ME, Neumark-Sztainer $D$ and Paxton SJ. Five-year change in body satisfaction among adolescents. J Psychosom Res. 2006; 61:521-7. | Article | PubMed

25. Ohring R, Graber JA and Brooks-Gunn J. Girls' recurrent and concurrent body dissatisfaction: correlates and consequences over 8 years. Int J Eat Disord. 2002; 31:404-15. | Article | PubMed

26. Davison KK, Werder JL, Trost SG, Baker BL and Birch LL. Why are early maturing girls less active? Links between pubertal development, psychological well-being, and physical activity among girls at ages 11 and 13. Soc Sci Med. 2007; 64:2391-404. | Article | PubMed Abstract | PubMed Full Text

27. Brooks-Gunn J and Warren MP. The psychological significance of secondary sexual characteristics in nine- to eleven-year-old girls. Child Dev. 1988; 59:1061-9. | Article | PubMed

28. Currie C, Nic Gabhainn S and Godeau E. The Health Behaviour in Schoolaged Children: WHO Collaborative Cross-National (HBSC) study: origins, concept, history and development 1982-2008. Int J Public Health. 2009; 54 Suppl 2:131-9. | Article | PubMed

29. Carskadon MA and Acebo C. A self-administered rating scale for pubertal development. J Adolesc Health. 1993; 14:190-5. | Article | PubMed

30. Cole TJ, Bellizzi MC, Flegal KM and Dietz WH. Establishing a standard definition for child overweight and obesity worldwide: international survey. BMJ. 2000; 320:1240-3. | Article | PubMed Abstract | PubMed Full Text 
Van Vliet et al. Paediatrics and Health 2014,

http://www.hoajonline.com/journals/pdf/2052-935X-2-1.pdf

doi: 10.7243/2052-935X-2-1

31. McCarthy HD, Jarrett KV and Crawley HF. The development of waist circumference percentiles in British children aged 5.0-16.9 y. Eur J Clin Nutr. 2001; 55:902-7. | Article | PubMed

32. Siegel JM, Yancey AK, Aneshensel CS and Schuler R. Body image, perceived pubertal timing, and adolescent mental health. J Adolesc Health. 1999; 25:155-65. | Article | PubMed

33. Andrist LC. Media images, body dissatisfaction, and disordered eating in adolescent women. MCN Am J Matern Child Nurs. 2003; 28:119-23. Article I PubMed

34. Rhodes SK and O'Neil PM. Effects of body fat distribution on body size estimation accuracy among obese women. Int J Obes Relat Metab Disord. 1997; 21:250-3. | Article | PubMed

35. Bergstrom E, Stenlund $H$ and Svedjehall B. Assessment of body perception among Swedish adolescents and young adults. J Adolesc Health. 2000; 26:70-5. | Article | PubMed

36. Riley AW. Evidence that school-age children can self-report on their health. Ambul Pediatr. 2004; 4:371-6. | Article | PubMed

37. Biro FM. Secular trends in menarche. J Pediatr. 2005; 147:725-6. | Article I PubMed

38. Juul A, Teilmann G, Scheike T, Hertel NT, Holm K, Laursen EM, Main KM and Skakkebaek NE. Pubertal development in Danish children: comparison of recent European and US data. Int J Androl. 2006; 29:24755. | Article | PubMed

39. Aksglaede L, Sorensen K, Petersen JH, Skakkebaek NE and Juul A. Recent decline in age at breast development: the Copenhagen Puberty Study. Pediatrics. 2009; 123:e932-9. | Article | PubMed

40. Biro FM, Greenspan LC and Galvez MP. Puberty in girls of the 21st century. J Pediatr Adolesc Gynecol. 2012; 25:289-94. | Article | PubMed Abstract | PubMed Full Text

41. Wohlfahrt-Veje C, Andersen HR, Schmidt IM, Aksglaede L, Sorensen K, Juul A, Jensen TK, Grandjean P, Skakkebaek NE and Main KM. Early breast development in girls after prenatal exposure to non-persistent pesticides. Int J Androl. 2012; 35:273-82. | Article | PubMed

42. Ojala K, Tynjala J, Valimaa R, Villberg J and Kannas L. Overweight Adolescents' Self-Perceived Weight and Weight Control Behaviour: HBSC Study in Finland 1994-2010. J Obes. 2012; 2012:180176. | Article | PubMed Abstract | PubMed Full Text

43. Currie C. International reports. 2013. | Website

\section{Citation:}

Van Vliet JS, Rasanen L, Gustafsson PA and Nelson $\mathrm{N}$. Overweight perception among adolescent girls in relation to appearance of female characteristics. Paediatr Health. 2014; 2:1.

http://dx.doi.org/10.7243/2052-935X-2-1 